\title{
Crew Dispatch for Network Services in an Electricity Utility Using Ant Colony Optimization Methodology
}

\author{
Paulo Baumann ${ }^{1}$, Tiago Miranda ${ }^{1}$, Fabio Romero ${ }^{1}$, João Castilho Neto ${ }^{1}$, Alden Antunes ${ }^{1}$, Dário \\ Takahata $^{1}$, Leonardo Ferreira Neto ${ }^{1}$, Angelo Alves ${ }^{2}$, Luisa Azevedo ${ }^{2}$, Sérgio Valinho ${ }^{2}$
}

\begin{abstract}
This paper presents an application of the Ant Colony Optimization methodology for the dispatch of field crews for realizing work orders in an electricity utility. The methodology takes as input a set of service calls and the importance of meeting each of them. The algorithm is able to create the routes to be taken by each team and the sequence in which they will be met taking into account the benefits of meeting a certain work order as well as the impact of not meeting it. This study is of great relevance and complexity because it dynamically optimizes the use of the potential capacity of the available crew, increasing their efficiency and enabling the Company to be prepared to unpredictable situations. A computer programme has been developed to apply this method and the results have been considered better than the ones from the current methods used by the Company and from others available on the literature. Also, it is more suitable for real time daily applications.
\end{abstract}

Keywords - Ant colony optimization; commercial and technical work orders; crew dispatch; real-time assignments.

\section{INTRODUCTION}

$\mathrm{T}$ HE study presented presented on this paper is part of a Research and Development (R\&D) Project of ANEEL (Brazilian Electricity Regulatory Agency), developed jointly by Maranhão Electricity Company (CEMAR) and Daimon Engineering \& Systems. CEMAR is a private-owned electric distribution utility, located in the northern region of Brazil which supplies over 2,000,000 customers, in the state of Maranhão, in Brazil.

Currently, at CEMAR (and at many other Brazilian electric utilities), just a few variables are taken into account by the utility's dispatchers when the assignment of work order is needed. They make their decisions based on previous knowledge, usually intuitively or by ad hoc methods. Also, the decisions are not re-evaluated even if the circumstances are different.

One should point out that the computer tool called ANTECOM (Ant Colony Tool for Prioritizing and Dispatching Technical and Commercial Work Orders) comprises two different modules: The former uses the

\footnotetext{
${ }^{1}$ Daimon Engineering \& Systems

${ }^{2}$ Energy Company of Maranhão.
}

Macbeth (Measuring Attractiveness by a Categorical Based Evaluation Technique) approach, which is a multi-criteria decision method [1] for the prioritization of commercial and supply restoration services in an electricity company. The latter is the content of the present paper, which uses the Ant Colony Optimization (ACO) methodology [2], in order to assign the services to be met, its sequence and the route to be taken by each available field crew.

Brazilian distribution companies are obliged to meet some quality of service standards, as from the commercial standpoint, as from the technical one. If they fail to meet the level of service required, then customers may be entitled to a payment. In the case of technical services, for instance, the amount paid to customers depends on many factors, such as the cause of the interruption, the accumulated number of times within a certain month, in which the supply has been interrupted, and the amount of time the supply has been interrupted.

\section{OBJECTIVES}

This paper presents a methodology and its correspondent computer programme based on concepts of Ant Colony Optimization methodology which will yield a real-time assignment list of available field crews to meet services demanded by consumers from telephone calls (as commercial as technical work orders) in a real-time basis. The goal is to meet several criteria simultaneously, forming a multi-objective problem, on which there is a compromising solution to meet commercial and technical issues, besides meeting less tangible issues, such as damage to the utility's image. Amongst the tangible goals, one can quote:

a) Reduce the payments realized from CEMAR to its customers for not meeting technical standards [3] and commercial ones [4];

b) Meet CEMAR's variables which have been considered relevant according to their importance level, as follows:

- Commercial Standards: Client importance, compensation for violating the time duration of commercial standard, complaint origin, meeting rate within pre-established 
time in order to meet the monthly standard, meeting rate within pre-established time in order to meet the annual standard, commercial service meeting rate in order to meet the monthly production standard, and commercial service meeting rate in order to meet the annual production standard;

- Technical Standards: Monthly SAIDI, annual SAIDI, compensation for violating individual reliability standards, reason for starting the complaint, client importance, number of recalls, number of re-incidences; and remaining time to violate 24 -hour deadline.

\section{ANT COLONY OPTIMIZATION}

The Ant Colony Optimization (ACO) belongs to a metaheuristic group based on populations. This method can be used to solve the crew dispatch problem, in which there is a set of places to be visited and, in each of them, there is a prize to be taken by the visiting team (in this case, the prize is a work order). Once a team arrived at the point and received the prize, no other team can receive it. The goal is to maximize the total prize.

This technique has been inspired by the fact that ants from a colony guide themselves by a trail of pheromones, searching for the best path to their food source. Good trails are chosen more often, making its pheromone concentration greater as well as the likelihood of it being chosen again. However, some ants can explore other possibilities, trying to find paths that are even better than the previous ones.

The problem can be presented as a graph. The work locations are the vertices and the paths are the edges. In ACO algorithms, an ant represents a solution. When constructing a solution, each ant is put on a starting point and then wanders randomly from vertex to vertex in the graph. At each vertex, an ant probabilistically selects the next vertex according to a decision policy or transition rule, which depends on the pheromone trails and on the heuristic information on the edges. Also, they deposit pheromone in the edges in order to attract other ants towards the corresponding area of the search space. The pheromones can evaporate, allowing some past history to be forgotten, and helping diversify the search to new and hopefully more promising areas of the search space.

During the construction of a solution, an ant chooses a feasible path for each vehicle (a field crew). The choice method depends on the variation of the ACO algorithm to be used. There are four variations: sequential, deterministicconcurrent, random-concurrent and simultaneous. For the simultaneous case, applied to this research, at first, all the possible vehicle-vertex pairs are considered. Then, the probability of each pair is calculated according to the pheromone trails and the heuristic information. Thus, one of these pairs is chosen respecting its probability. Subsequently, the problem constraints are verified and the set of vehiclevertex pairs are updated. The process goes on until there is no more possible pairs.

A fixed number of ants/solutions is predefined within a cycle (the amount of cycles is also defined previously). A solution consists of a set of routes, one for each vehicle/team. In a cycle, all ants independently try to find the better routes for the vehicles. In the next cycle, the ants will be influenced by the pheromones left by the ones from the previous cycles. At the end of the process, the solution that maximizes the prize is chosen.

\section{MethODOLOGY}

\section{A. The System}

The goal of a dispatch centre is to assign the work orders (WOs) to the most suitable road crew taking into account the benefits of meeting a certain service as well as the impact of not meeting it. The attribution should consider the execution average time by service and by team, team location, acting area, expected travel time, maximum and minimum Standard Service Unities (SSUs - it is a time unity used to quantify the duration of realized work of the field crews, varying from team to team according to the average travel time in its acting area) to be accomplished, team shift duration, availability, connectivity, vehicle type, vehicle traction type and team costs matrix.

The characteristics of the region met by CEMAR and due to the set of Brazilian regulation laws of the electricity system require some rules that must be considered by the dispatch system. The main rules are presented as follows:

Crew dispatch for shut-off works due to non-payment bills must start at 7:00 am or as close to it as possible; and these shut-off works must be done before 4:00 pm;

Shut-off work orders will not be assigned by the dispatch system. The dispatch manager does it manually;

Works that are manually assigned to a certain crew must be met firstly;

No work order may interfere in another one that is currently being met;

Shut-off works due to non-payment must be done before 4:00 pm;

The shut-off location (pole, meter, secondary network) should be evaluated when dispatching crews for reconnection services;

Each crew must meet a minimum and a maximum number of SSUs. Violations above the maximum limit are tolerated;

Solutions of which a field crew could not achieve its production target must not be considered;

The standard service duration, measured in SSU, varies according to service, team and Regional Agency;

The lunch break duration is of 2 hours;

Commercial WOs can be realized at any working time;

A work order must be located in the team acting area;

The crew must be able to receive messages from the operation manager;

The vehicle used by the crew must suit the WO;

The WO can only be assigned to a team if there is enough time of it to be met before its shift ends.

In order to estimate the time to be spent by a team to meet the assigned WOs and make sure they can be realized before the end of the shift, it is necessary to measure the assistance duration and travel time. The assistance duration will be 
estimated by the average time spent by the team in that type of service. The distances and travel times between WOs are calculated using mapping web tools, like Google Maps. Alternatively, the linear distance between the coordinates and the average speed can be used to calculate the travel time.

The system assumes the existence of a previous system able to define the SC's importance and that the importance of each of them can vary through time. Also, in some days, there will be WOs that cannot be assisted. Knowing that, the most important WOs should be met preferably.

The work orders (WOs) in this study comprise 3 different types of services carried out by the road crews, and their characteristics are briefly explained as follows:

Shut-off orders: Disconnection procedures applied to the customers who failed to pay the electricity bills. These orders are scheduled at the night before and should be accomplished in the morning of the next day, starting preferably at 07:00 a.m., before the other type of orders;

Commercial orders: These are service orders requested by the consumers for instance, to check their meters, realize new connections, realize reconnection after paying their debts, etc. These services are accomplished during the time band of working days (if the commercial standard is in working days) or hours (if the commercial standard is in hours, like, for instance, a judicial reconnection, whose deadline is within 4 hours);

Emergency orders: These are technical service orders, primarily to reestablish energy supply after a fault and are opened around the clock. One should point out that voltage complaints, although having a technical character, according to Brazilian legislation, belong to the previous item. In short, emergency orders have to do with disconnection of customers and safety issues and may be accomplished at any time.

\section{B. The Solution}

A solution is valid if it defines a set of routes containing the WO's to be met by a crew observing the previously mentioned constraints. The best solution will be the one that minimizes the sum of the importance of the non-assisted WOs and minimizes the sum of the assisted WOs, ordered by preference.

The lexicographic method will be used here. In this method, capable of finding an optimal solution, it is given maximum importance to the first target. In case just one solution is found when minimizing the first function, it is chosen and the other targets are not evaluated. In case there are multiple solutions, the next step is to minimize the second most important target and so on. From the second minimization, a new constraint is considered to make sure the value from the previous target does not increase [5].

However, due to possible inaccuracies on the importance classification, two parameters varying to $\pm 10 \%$ are considered equal when comparing solutions and then the next target is evaluated.

\section{RESULTS}

A fictitious and simplified situation has been proposed in order to illustrate the results that can be obtained by the new methodology. Thus, 36 WOs have been created and prioritized according to the company's interests and the final score of each solution to be presented next was calculated based on it. The dispatch algorithm has been applied to this example. Also, the current dispatch method (mainly intuitively) has been applied by CEMAR's operator in order to make a comparison of the two methods.

Fig. 1 present a map of São Luis with 36 pending WOs which should be assigned to 3 road crews on December 5th 1915 at 09:00 a.m. across the city of São Luis, in Maranhão, Brazil, as if these WOs were in a real-time environment within CEMAR's Dispatch Centre. The current method used nowadays by CEMAR is basically intuitive with very simple restrictions, like avoiding the presence of crews in the same acting region.

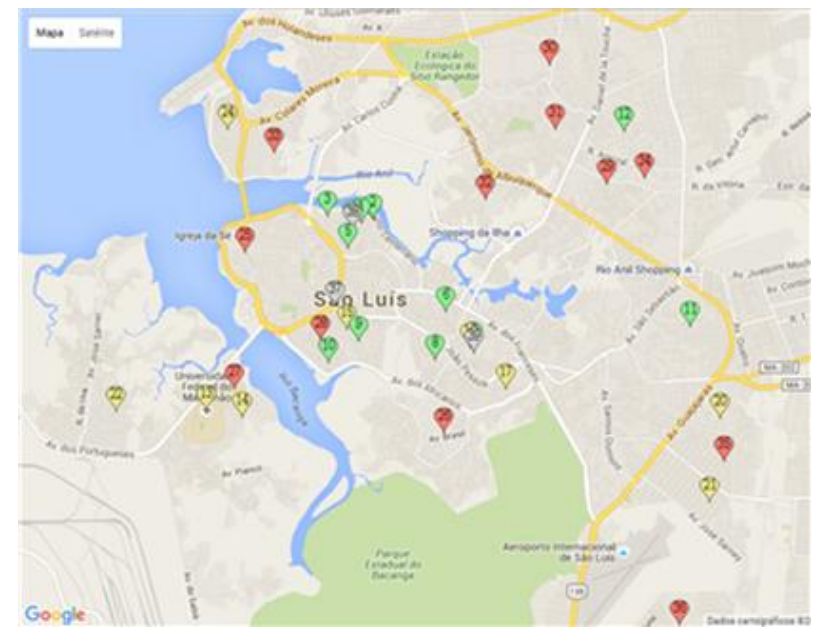

Fig. 1: Map of São Luis with 36 Pending Work Orders

According to Fig. 1, the red balloons represent the emergency work orders, the yellow ones represent the commercial work orders, the green ones represent shut-off work orders and finally, and the grey balloons represent the road crews, located at 09:00 a.m. on December 5th 1915, on the streets of São Luis, in Maranhão. Therefore, as one can see on Fig. 1, the algorithm has to find out an optimized solution in order to meet these 36 pending WOs through the 3 field crews as quickly as possible

Table 1 presents a list of the pending Shut-off Work Orders which appears on the screen of CEMAR's OPER (Electric Distribution System Operational Management) at 09:00 am.

One should stress that the shut-off work orders do not cause any kind of regulatory penalty to the utility by not meeting some kind of standard, because in Brazil there is no standard regarding shut-off clients. It is up to the utility to reduce the amount of pending electricity bills, in order to diminish its commercial losses. 
TABLE I

LIST OF PENDING SHUT-OFF WORK ORDERS

\begin{tabular}{ccc}
\hline \hline $\begin{array}{c}\text { Shut-off Work Order } \\
\text { (SWO) }\end{array}$ & $\begin{array}{c}\text { Customer's } \\
\text { accumulated Debt } \\
\text { (US\$) }\end{array}$ & $\begin{array}{c}\text { Process started before } \\
\text { dispatch (hours) }\left({ }^{1}\right)\end{array}$ \\
\hline 01 & 200.00 & 24 \\
02 & 200.00 & 24 \\
03 & 200.00 & 18 \\
04 & 200.00 & 96 \\
05 & $1,000.00$ & 24 \\
06 & $1,000.00$ & 24 \\
07 & $1,000.00$ & 24 \\
08 & $1,000.00$ & 18 \\
09 & $5,000.00$ & 24 \\
10 & $5,000.00$ & 24 \\
11 & $5,000.00$ & 24 \\
12 & $10,000.00$ & 24 \\
\hline \hline
\end{tabular}

$\left.{ }^{1}\right)$ Dispatch time: 09:00 a.m. on December 5th 1915

Table 2 presents a list of the pending Commercial Orders which appears on the screen of CEMAR's OPER, at the same time of the day as the Table 1 .

How quick the commercial work orders should be assisted depends on the importance of the client to the utility as well, according to the classification index. Primary importance means that this type of customer is the most important one to the utility, followed by the secondary client and by the tertiary one.

Additionally, how the work order has been tagged by the utility's Call-Centre or reception desk is also relevant. The consumer request may be started as an ordinary order via telephone call into the Call-Centre (the majority of cases), or sometimes, via court order through a judge, who demands the customer to be reconnected within a certain time period.

TABLE II

LIST OF PENDING COMERCIAL WORK ORDERS

\begin{tabular}{cccccc}
\hline \hline $\begin{array}{c}\text { Commerci-al } \\
\text { Work Order } \\
(\mathrm{CWO})\end{array}$ & $\begin{array}{c}\text { Client im- } \\
\left.\text { portance }{ }^{1}\right)\end{array}$ & $\begin{array}{c}\text { Type of } \\
\text { request }\end{array}$ & $\begin{array}{c}\text { Client's } \\
\text { average } \\
\text { bill (US } \$ \text { ) }\end{array}$ & $\begin{array}{c}\text { Process } \\
\text { started }\left(^{2}\right) \\
\text { (hours) }\end{array}$ & $\begin{array}{c}\text { Deadline } \\
\text { (hours) }\end{array}$ \\
\hline 01 & $\mathrm{~S}$ & Ordinary & $5,000.00$ & 24 before & 8 \\
02 & $\mathrm{~S}$ & Ordinary & $5,000.00$ & 3 after & 32 \\
03 & $\mathrm{~S}$ & Ordinary & $5,000.00$ & 6 after & 32 \\
04 & $\mathrm{~S}$ & Judicial & $5,000.00$ & 18 before & 32 \\
05 & $\mathrm{~S}$ & Ordinary & $5,000.00$ & 24 before & 8 \\
06 & $\mathrm{P}$ & Ordinary & $5,000.00$ & 3 after & 32 \\
07 & $\mathrm{P}$ & Judicial & $5,000.00$ & 18 before & 32 \\
08 & $\mathrm{P}$ & Judicial & $15,000.00$ & 24 before & 32 \\
09 & $\mathrm{~S}$ & Ordinary & $15,000.00$ & 24 before & 32 \\
10 & $\mathrm{~S}$ & Ordinary & $15,000.00$ & 6 after & 32 \\
11 & $\mathrm{~S}$ & Ordinary & 500.00 & 24 before & 8 \\
12 & $\mathrm{~S}$ & Judicial & 500.00 & 24 before & 32 \\
\hline \hline
\end{tabular}

( $\left.{ }^{1}\right)$ P - Primary; S - Secondary; T - Tertiary

$\left({ }^{2}\right)$ Dispatch time: 09:00 a.m. on December 5th 1915

Table 3 presents a list of the pending Emergency Work Orders which appears on the screen of CEMAR's OPER, at the same time of the day as the Table 1 and 2.

Thus, the challenge of ANTECOM is to optimize the route of the 3 road crews in order to meet these 36 pending WO's at 09:00 a.m. on December 5th 1915, considering their characteristics and their respective impact by prioritizing a few orders in detriment of others, and also pondering the possibility of not meeting some of them.
TABLE III

LisT OF PENDING EMERGENCY WORK ORDERS

\begin{tabular}{cccccc}
\hline \hline $\begin{array}{c}\text { Emergency } \\
\text { Work Order } \\
(\text { EWO) }\end{array}$ & $\begin{array}{c}\text { Clients } \\
\text { importance } \\
\left({ }^{2}\right)\end{array}$ & $\begin{array}{c}\text { Com- } \\
\text { plaints } \\
\left({ }^{1}\right)\end{array}$ & $\begin{array}{c}\text { Recal } \\
\text { ls }\left(^{3}\right)\end{array}$ & $\begin{array}{c}\text { Reinci- } \\
\text { dences } \\
\left({ }^{4}\right)\end{array}$ & $\begin{array}{c}\text { Process started } \\
\text { before dispatch } \\
\left({ }^{5}\right) \\
\text { (hours) }\end{array}$ \\
\hline 01 & $\mathrm{P}$ & $\mathrm{G}$ & 15 & 0 & 2 \\
02 & $\mathrm{P}$ & $\mathrm{G}$ & 10 & 2 & 2 \\
03 & $\mathrm{P}$ & $\mathrm{G}$ & 10 & 0 & 2 \\
04 & $\mathrm{~S}$ & $\mathrm{G}$ & 5 & 5 & 24 \\
05 & $\mathrm{~S}$ & $\mathrm{G}$ & 5 & 3 & 24 \\
06 & $\mathrm{~T}$ & $\mathrm{I}$ & 0 & 5 & 24 \\
07 & $\mathrm{~T}$ & $\mathrm{I}$ & 0 & 0 & 24 \\
08 & $\mathrm{~S}$ & $\mathrm{I}$ & 0 & 0 & 0 \\
09 & $\mathrm{~S}$ & $\mathrm{I}$ & 0 & 0 & 19 \\
10 & $\mathrm{~S}$ & $\mathrm{I}$ & 0 & 0 & 17 \\
11 & $\mathrm{~T}$ & $\mathrm{I}$ & 0 & 0 & 0 \\
12 & $\mathrm{~T}$ & $\mathrm{I}$ & 0 & 0 & 0 \\
\hline \hline
\end{tabular}

( ${ }^{1}$ ) I - Individual request; $\mathrm{G}$ - Group of consumers reques.t

( $\left.{ }^{2}\right)$ P-Primary; S - Secondary; T - Tertiary.

$\left({ }^{3}\right)$ Number of telephone calls from the same client.

$\left({ }^{4}\right)$ Number of times that the same fault ocurred within, for instance, a month.

$\left({ }^{5}\right)$ Dispatch time: 09:00 a.m. on December 5th 1915.

\section{A. CEMAR's Crews Trajectories}

In order to compare the performances of ANTECOM and the method currently used by CEMARS's dispatchers, Figs. 2 4 show the trajectories of the 3 road crews (grey balls of Fig. 1), initially located on the streets of São Luis, in Maranhão at 09:00 a.m. on December 5th 1915. From then on, each crew visited the work orders according to the instructions of the Dispatch Centre of CEMAR, as shown on Table IV.

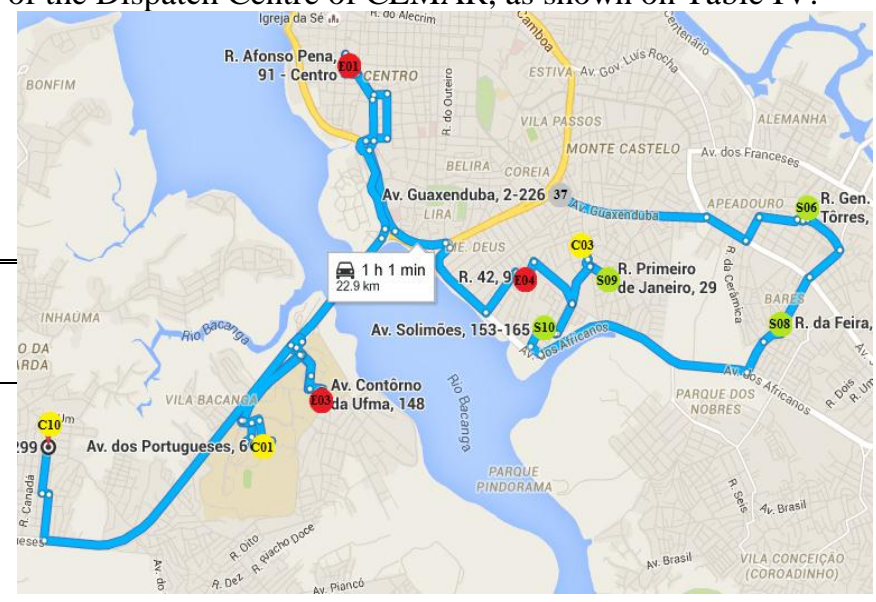

Fig. 2 Trajectory of the \#37 road crew, from 09:00 am onwards

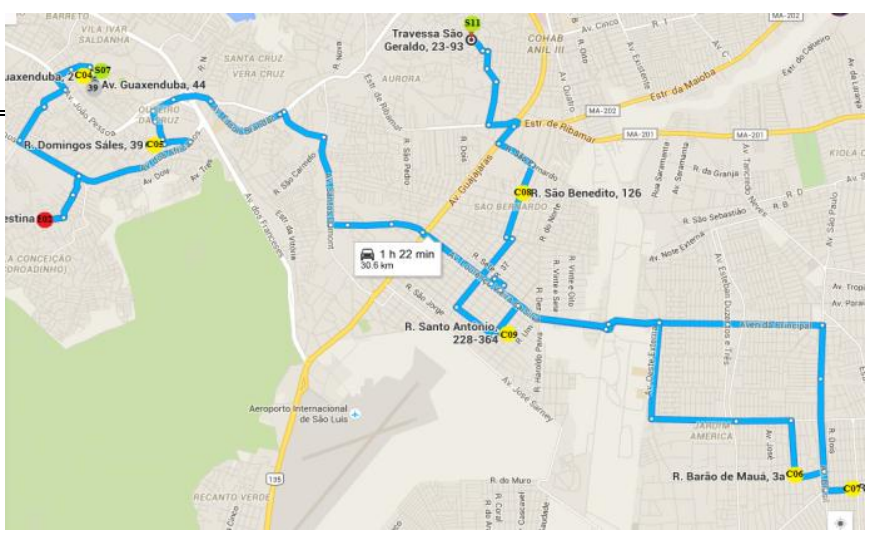

Fig. 3 Trajectory of the \#38 road crew, from 09:00 am onwards 


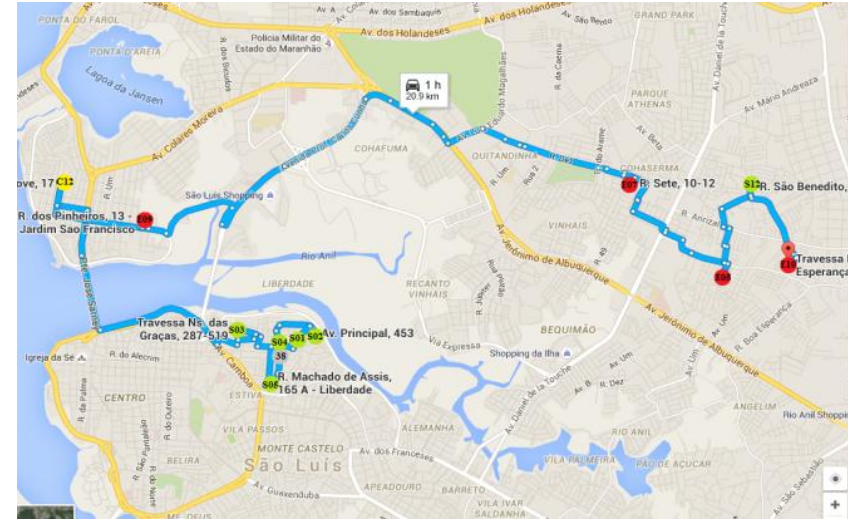

Fig. 4 Trajectory of the \#39 road crew, from 09:00 am onwards

TABLE IV

LIST OF WORK ASSIGNMENTS TO FIELD CREWS DISPATCHED BY CEMAR

\begin{tabular}{|c|c|c|c|}
\hline \multirow{2}{*}{$\begin{array}{c}\text { Work Order } \\
\text { Sequence }\end{array}$} & \multicolumn{3}{|c|}{ Road Crew } \\
\cline { 2 - 4 } & $\# 37$ & $\# 38$ & $\# 39$ \\
\hline 1 & $\mathrm{~S} 06$ & $\mathrm{~S} 04$ & $\mathrm{C} 04$ \\
\hline 2 & $\mathrm{~S} 08$ & $\mathrm{~S} 02$ & $\mathrm{~S} 07$ \\
\hline 3 & $\mathrm{~S} 10$ & $\mathrm{~S} 01$ & $\mathrm{E} 02$ \\
\hline 4 & $\mathrm{~S} 09$ & $\mathrm{~S} 05$ & $\mathrm{C} 05$ \\
\hline 5 & $\mathrm{C} 03$ & $\mathrm{~S} 03$ & $\mathrm{C} 07$ \\
\hline 6 & $\mathrm{E} 04$ & $\mathrm{C} 12$ & $\mathrm{C} 06$ \\
\hline 7 & $\mathrm{E} 01$ & $\mathrm{E} 09$ & $\mathrm{C} 09$ \\
\hline 8 & $\mathrm{E} 03$ & $\mathrm{E} 07$ & $\mathrm{C} 08$ \\
\hline 9 & $\mathrm{C} 01$ & $\mathrm{E} 05$ & $\mathrm{~S} 11$ \\
\hline 10 & $\mathrm{C} 10$ & $\mathrm{~S} 12$ & \\
\hline 11 & & $\mathrm{E} 10$ & \\
\hline Labour hours & $\mathbf{8}$ & $\mathbf{8}$ & $\mathbf{8}$ \\
\hline
\end{tabular}

As one can see by Table IV, \# 37 road crew starts at 09:00 am heading towards the location of S06 work order, and after finishing its job, goes to the next work order (S08), and so on, successively, until its last work order of the day (C10). The same procedure happens to the other 2 road crews. The Figs. 2 - 4 show the trajectory of \# 37, \# 38 and \# 39 road crews, respectively, from 09:00 am onwards.

As predicted, CEMAR's solution has some inaccuracies, once it has been intuitively built and could not take into account all the problem's constraints. In this example, the dispatcher has not considered the displacement time, so it would not be possible to meet all the work orders pointed by them. Also, he has forgotten that WO C03 could only be met at $3 \mathrm{pm}$ onwards, nonetheless tried to meet it earlier.

In order to measure the effectiveness of CEMAR's solution, its dispatch was simulated by ANTECOM's for solution comparison. The simulation, however, took into account the road crews shift duration and all the other constraints. In the new result, the WOs E01, E03, C01, C10 and S11 could not be met as well as the other WOs unattended by the previous solution. The final score of non-assisted WOs of the solution was 852.04 (the higher the score, the worse is the solution).

\section{B. CEMAR's Crews Trajectories}

Table $\mathrm{V}$ shows the WO met by each road crew according to ANTECOM's dispatch. Figs. 5 to 7 show the trajectory of \# 37, \# 38 and \# 39 road crews, respectively, from 09:00 am. onwards.
Comparing both solutions, it is possible to notice that CEMAR tried to minimize the routes to be taken and the work orders importance seemed to be less explored, while ANTECOM's approach was able to make the company's interests more relevant to the solution. The final score of nonassisted WO's of ANTECOM's solution is 258.84, an improvement of $229 \%$.

TABLE V

LIST OF WORK ASSIGNMENTS TO FIELD CREWS DISPATCHED BY ANTECOM

\begin{tabular}{|c|c|c|c|}
\hline \multirow{2}{*}{$\begin{array}{c}\text { Work Order } \\
\text { Sequence }\end{array}$} & \multicolumn{3}{|c|}{ Road Crew } \\
\cline { 2 - 4 } $\mathbf{1}$ & $\# 37$ & $\# 38$ & $\# 39$ \\
$\mathbf{2}$ & S12 & S09 & S10 \\
$\mathbf{3}$ & S11 & E03 & E02 \\
$\mathbf{4}$ & C08 & C12 & E09 \\
$\mathbf{5}$ & C06 & S04 & E01 \\
$\mathbf{6}$ & C07 & S01 & E05 \\
$\mathbf{7}$ & E10 & S02 & C04 \\
$\mathbf{8}$ & E06 & S05 & S07 \\
$\mathbf{9}$ & & S03 & S06 \\
$\mathbf{1 0}$ & & E04 & \\
Labour hours & & S08 & \\
\hline \hline
\end{tabular}

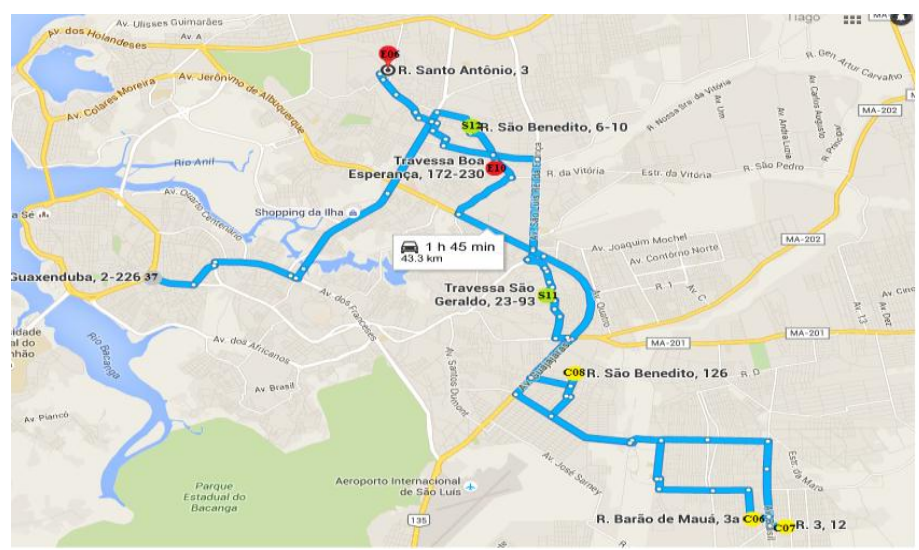

Fig. 5 Trajectory of the \#37 road crew, from 09:00 am onwards

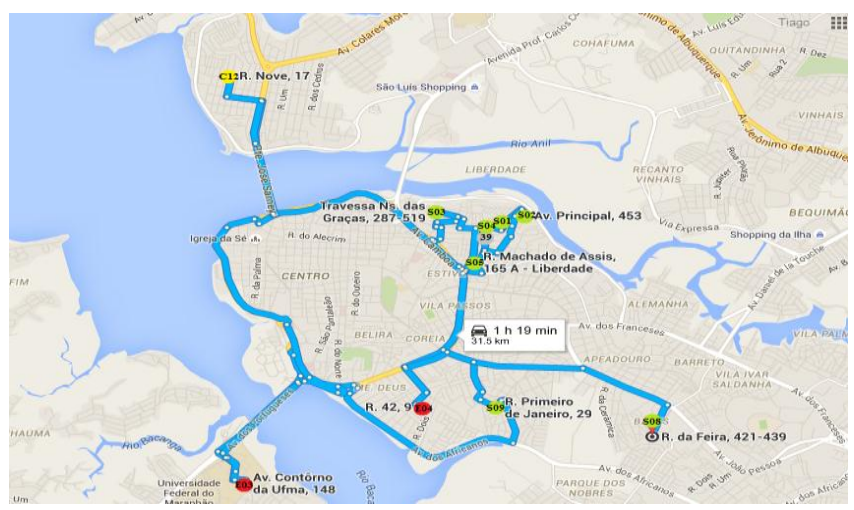

Fig. 6. Trajectory of the \#38 road crew, from 09:00 am onwards 


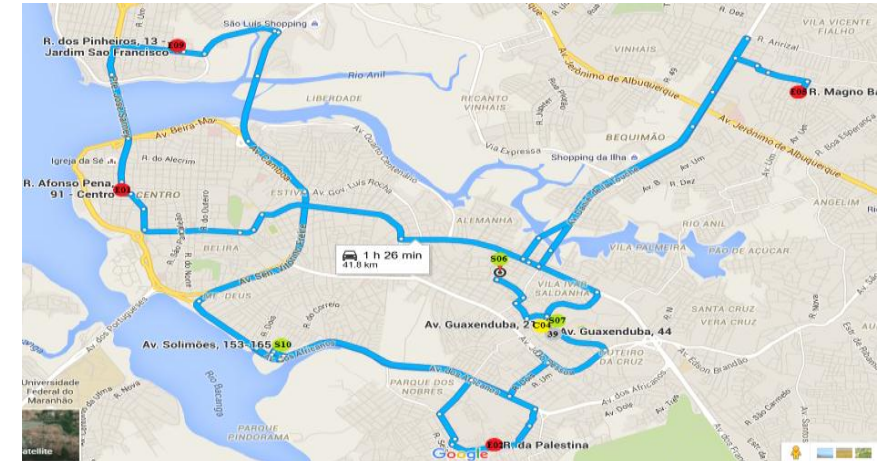

Fig. 7 Trajectory of the \#38 road crew, from 9:00 am onwards

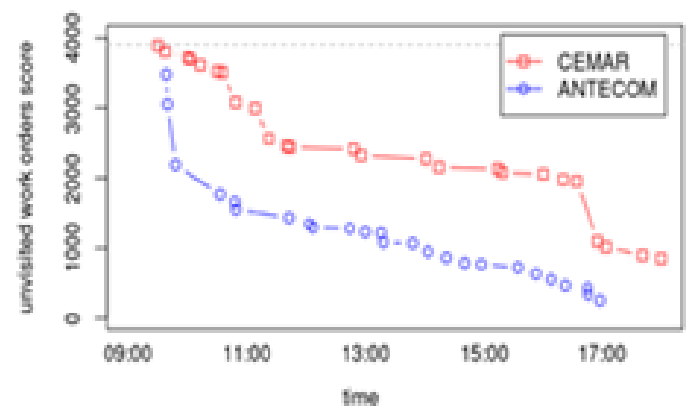

Fig. 8 Non-visited WO's score throughout the day

Fig. 8 shows a graph of the scores of non-assisted WOs of both CEMAR and ANTECOM dispatch throughout the day. One can see that ANTECOM presented the best score all day long.

\section{CONCLUSION}

Dispatching field crews is a nonstop process, compelled by the arrival of new work orders, weather conditions, loss of connectivity etc. It is a very hard work to the Dispatch Centre to keep the electric systems working, taking into account the changing circumstances. ANTECOM is a tool to help the utility to face this task, providing an optimized way to prioritize and assign the work orders to the available road crew. The latter is the subject of this paper, using the Ant Colony Optimization (ACO) methodology, providing an optimized work orders sequence and routes to be taken by each available field crew.

According to the simulated merit indexes, the solution score of CEMAR's unattended WOs was 852.04, whereas ANTECOM's score was 258.8. The former reflected the decisions made by CEMAR's dispatchers based on previous knowledge, intuition and experience, which also may present an inaccurate response due to the real-time amount of information and pressure. The latter implemented the simultaneous ACO algorithm to optimize the result according to the number of field crews available and to the company's main goals.

The product developed offers to CEMAR, to the technical community and to society an important tool that is not yet contemplated by the current systems. Also, by its capacity to evaluate - in a totally automatic way - all the variables considered relevant by the company in real time and dynamically, the product is a sophisticated tool.

\section{REFERENCES}

[1] Bana e Costa, C. A.; Corte, J. M.; Vansnick, J. C. "On the mathematical foundation of MACBETH." In: Figueira, Jose, Greco, Salvatore and Ehrgott, Matthias, (eds.) Multiple Criteria Decision Analysis: the State of the Art Surveys. International series in operations research \& management science. Springer, New York, USA, pp. 409-442. ISBN $038723067 X, 2005$. http://dx.doi.org/10.1007/0-387-23081-5_10

[2] Ke, Liangjun; Archetti, C.; Feng, Z. "Ants can solve the team orienteering problem." Computers \& Industrial Engineering, v. 54, n. 3, 2008, pp. 648-665. http://dx.doi.org/10.1016/j.cie.2007.10.001

[3] ANEEL (Brazilian Electricity Regulatory Agency). Normative Resolution \#345/2008, issued on 16 December 2008 and subsequent amendments.

[4] ANEEL (Brazilian Electricity Regulatory Agency). Normative Resolution \#414/2010, issued on 9 September 2010.

[5] Denis Bouyssou, Thierry Marchant, Marc Pirlot, Alexis Tsoukiàs, Philippe Vincke. "The lexicographic method," in Evaluation and decision models with multiple criteria: Stepping stones for the analyst, v. 86. [S.I.]: Springer Science \& Business Media, 2006, pp. 188-190. 